\title{
THE NORMAL RESTING CARDIAC OUTPUT: SERIAL DETERMINATIONS BY A DYE DILUTION METHOD
}

\author{
BY \\ THOMAS A. BRUCE* AND JOHN P. SHILLINGFORD \\ From the Department of Medicine, and the Medical Research Council Research Group on Cardiovascular Disease, \\ Postgraduate Medical School, London, W.12. \\ Received August 30, 1961 \\ The resting output of the normal heart has been investigated by many workers (Krogh and \\ Lindhard, 1912; Christiansen et al., 1914; Stewart, 1921; Grollman, 1928; Hamilton et al., 1932; \\ Nylin, 1933; Berseus, 1943; McMichael and Sharpey-Shafer, 1944; Cournand et al., 1945; Stead et \\ al., 1945; Werko, 1947; Chapman et al., 1950; Doyle, et al., 1953; Donald et al., 1955; Goodyer \\ et al., 1960; Reeves et al., 1961). Several authors have drawn attention to the limitations of the \\ various methods used for the estimation of the cardiac output; these include the problem of achieving \\ a true basal state due to the mechanics and the excitement of the procedure itself and the difficulty \\ in obtaining reproducible results. With the development of a photoelectric earpiece giving a linear \\ response to concentration of dye (Gabe and Shillingford, 1961) and the use of Coomassie Blue dye \\ as an indicator (Taylor and Shillingford, 1959) it has now become possible to make reliable serial \\ determinations of the cardiac output in subjects lying comfortably at rest, without cardiac catheter- \\ ization and arterial puncture.
}

\section{METHODS}

Eleven physicians and 12 ambulatory hospital patients were studied. Both groups had a normal cardiovascular system on clinical examination. The mean age of all subjects was 33 years (range 16 to 55 years). There were eleven men and twelve women.

On the day before the procedure the subjects were given a brief description of the methods to be used in the study. Hospital patients were allowed to have tea at $6 \mathrm{a} . \mathrm{m}$. but no breakfast. Each was taken to the examination room in his bed at $8 \mathrm{a} . \mathrm{m}$. and the explanation of the procedure was repeated to lessen apprehension. The room was warm and quiet, and unnecessary instruments and equipment were removed from sight. The physicians were studied late in the afternoon, at least three hours after they had last eaten. No smoking was allowed for three hours before the procedure.

Subjects were made comfortable in the supine position. Histamine cream was applied to the pinna of the ear and a warmed earpiece cuvette (Cambridge Instrument Co.) attached. A size 18 indwelling needle was placed in the median antecubital vein after local infiltration with Xylocaine. A three-way stopcock was connected from the needle to a slow drip of normal saline. A smaller indwelling needle was placed in the opposite antecubital vein for subsequent blood sampling. Both arms remained freely movable during the procedure. The subjects were allowed to rest another 20-30 minutes before the first dye curve was made.

Twenty-five mg. of one per cent Coomassie Blue dye (Imperial Chemical Industries Ltd.) were rapidly injected into the vein from a calibrated syringe and the subject's arm was raised to improve

* U.S. Public Health Research Fellow. 
venous drainage. Events were recorded on a Mark II Cambridge Dye Recorder with a high resistance input circuit. The blood pressure and pulse rate were recorded immediately after the dye curve was completed. Venous samples were obtained at three and five minutes for plasma extraction of the dye. Dye curve estimations were repeated at five minute intervals.

Methods for calculation of the cardiac output have been described in detail (Hamilton et al., 1932). The cardiac output is equal to $\frac{I}{\mathrm{Ct}}$, where $\mathrm{I}$ is the amount of indicator injected, $\mathrm{C}$ is the average concentration of the indicator after its first circulation, and $t$ is the time required for the circulation of the indicator. Since the area under the recorded dye curve $=\mathrm{Ct}$ and the amount of indicator injected remains constant, the quotient I/Area can be used to calculate changes in cardiac output, thereby eliminating any additional error involved in converting it to absolute cardiac output by

TABLE I

Percentage Change of Successive Determinations

\begin{tabular}{|c|c|c|c|c|c|c|c|c|c|c|c|c|}
\hline No. & $\begin{array}{l}\text { Cardiac } \\
\text { output } \\
(1 / \mathrm{min})\end{array}$ & $\begin{array}{c}\text { Cardiac } \\
\text { index } \\
\left(1 / \mathrm{min} / \mathbf{M}^{2}\right)\end{array}$ & I & II & III & IV & V & VI & VII & VIII & $\begin{array}{l}\text { Standard } \\
\text { error of } \\
\text { the mean }\end{array}$ & $\begin{array}{c}\text { Maximum } \\
\text { distance } \\
\text { from the } \\
\text { mean }\end{array}$ \\
\hline 1 & $5 \cdot 18$ & $3 \cdot 34$ & $\begin{array}{l}\% \\
100\end{array}$ & $\%$ & $\%$ & $\%$ & $\%$ & $\%$ & $\%$ & $\begin{array}{l}\% \\
88\end{array}$ & $\begin{array}{l}\% \\
\pm 7\end{array}$ & $\begin{array}{l}\% \\
13\end{array}$ \\
\hline 2 & $\begin{array}{r} \pm 0.41 \\
5.11\end{array}$ & $\begin{array}{r} + \pm 0.26 \\
2.94\end{array}$ & 100 & 103 & 104 & 106 & 105 & 101 & 97 & 104 & 3 & 5 \\
\hline 3 & $\begin{array}{r}+0.52 \\
\pm 0.30\end{array}$ & $\begin{array}{r} \pm 0.08 \\
2.82 \\
\pm 0.16\end{array}$ & 100 & 96 & 109 & 107 & 100 & 94 & - & - & 5 & 8 \\
\hline 4 & - & - & 100 & 97 & 95 & 95 & 85 & 85 & - & - & 6 & 6 \\
\hline 5 & - & - & 100 & 97 & 80 & 91 & - & - & - & - & -8 & 10 \\
\hline 6 & - & - & 100 & 97 & 99 & $\begin{array}{c}99 \\
105\end{array}$ & 一 & - & - & - & 1 & 1 \\
\hline $\begin{array}{l}7 \\
8\end{array}$ & 二 & - & 100 & $\begin{array}{l}91 \\
78\end{array}$ & 114 & 105 & 二 & 二 & 二 & - & 10 & 9 \\
\hline$\stackrel{\circ}{9}$ & 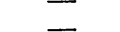 & 二 & 100 & $\begin{array}{l}10 \\
79\end{array}$ & $\begin{array}{l}01 \\
79\end{array}$ & - & - & - & - & 二 & 10 & 16 \\
\hline 10 & - & - & 100 & 96 & 108 & - & - & - & - & - & 5 & 6 \\
\hline 11 & - & 一 & 100 & 80 & 73 & - & - & - & - & - & 11 & 19 \\
\hline 12 & - & - & 100 & 100 & 91 & - & - & - & - & - & 4 & 6 \\
\hline 13 & $7 \cdot 06$ & 3.43 & 100 & 115 & 116 & 111 & 100 & 107 & 93 & 104 & 7 & 12 \\
\hline 14 & $\begin{array}{r} \pm .36 \\
\end{array}$ & $\begin{array}{r} \pm .57 \\
3.57\end{array}$ & 100 & 117 & 98 & 112 & 120 & 117 & 118 & 117 & 8 & 13 \\
\hline 15 & $\begin{array}{r} \pm 0.45 \\
5.80\end{array}$ & $\begin{array}{r} \pm 0.26 \\
2.91\end{array}$ & 100 & 101 & 111 & 100 & 96 & 91 & 94 & 90 & 6 & 8 \\
\hline & \pm 0.45 & \pm 0.22 & & & & & & & & & & \\
\hline 16 & $\begin{array}{r}5.57 \\
+0.76\end{array}$ & $\begin{array}{r}2.89 \\
+0.39\end{array}$ & 100 & 88 & 84 & 75 & 74 & 62 & 71 & 74 & 11 & 27 \\
\hline 17 & 4.68 & 2.85 & 100 & 96 & 95 & 98 & 96 & 99 & 98 & 103 & 2 & 4 \\
\hline 18 & \pm 0.12 & \pm 0. & 100 & 100 & 100 & 109 & 102 & 106 & 108 & 106 & 4 & 5 \\
\hline 19 & $\begin{array}{r}5.96 \\
+0.56\end{array}$ & $\begin{array}{r}3.68 \\
+0.34\end{array}$ & 100 & 99 & 88 & 85 & 79 & 80 & - & - & 8 & 13 \\
\hline 20 & 6.30 & 3.26 & 100 & 105 & 92 & 110 & - & - & - & - & 7 & 10 \\
\hline & \pm 0.42 & \pm 0.22 & 100 & 97 & 90 & 102 & - & - & - & - & 8 & 14 \\
\hline 22 & - & - & 100 & 97 & 90 & 102 & - & - & - & - & 4 & 7 \\
\hline 23 & - & - & 100 & 107 & 91 & -1 & - & - & - & - & 7 & 8 \\
\hline $\begin{array}{l}\text { Aver- } \\
\text { ages }\end{array}$ & $5 \cdot 75$ & $\begin{array}{r}3 \cdot 17 \\
\pm 0 \cdot 22\end{array}$ & 100 & 95 & 95 & 98 & 95 & 93 & 96 & 98 & $\pm 6 \%$ & $10 \%$ \\
\hline
\end{tabular}

Serial normal resting cardiac output determinations are listed for individual subjects, expressed as the percentage of the first determination. Mean absolute values obtained in 10 subjects are given with their standard deviations. Cardiac output is expressed as litres/minute; cardiac index as litres/minute/square metre body surface. 
plasma extraction and spectrophotometric estimation of the dye concentration. The relative cardiac outputs derived from changes in the curve areas are used in this report to compare variations in the normal resting state. All curves were replotted on semi-logarithmic paper to eliminate errors in recirculation.

\section{RESULTS}

One hundred and fifteen dilution curves were made on 23 subjects (Table 1). Eight of the subjects had eight serial determinations and the remainder three to six determinations each. The general contour of the successive earpiece curves in one individual is seen in Fig. 1. The average change in cardiac output for the whole group over the total series of determinations taken at five minute intervals is shown in Fig. 2. It will be seen that the average change did not exceed 7 per cent.

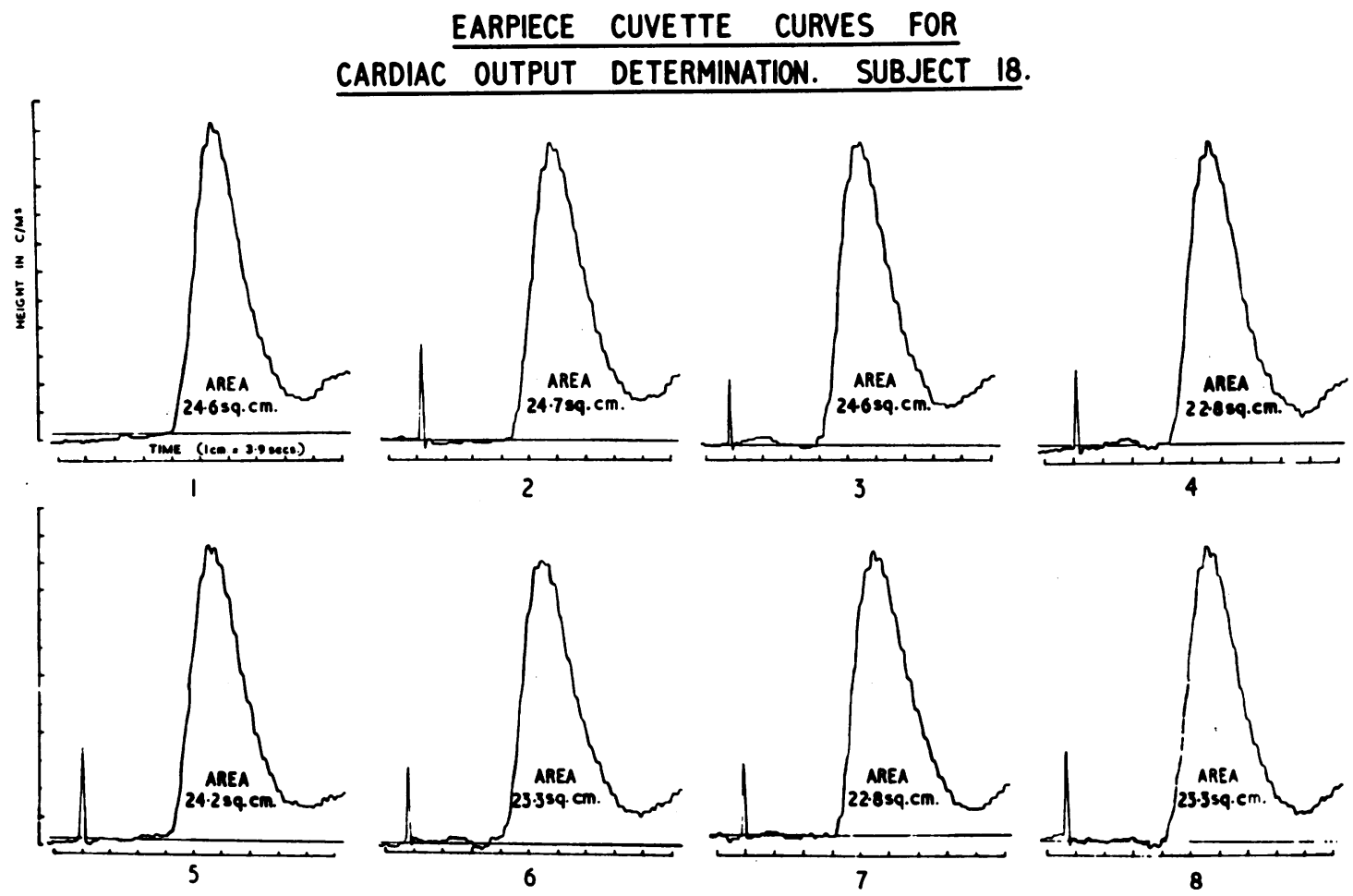

Fig. 1.-Serial due dilution curves from Subject No. 18 at five minute intervals, recorded from a photoelectric earpiece.

Fig. 3 shows the changes in the cardiac output in a subject who showed little variation (maximum fluctuation of 0.45 litre/minute in 8 determinations). On the other hand Fig. 4 shows the changes in the subject who exhibited the greatest alteration in the cardiac output. In this case the output fell to 62 per cent of the first determination over a period of 30 minutes. This was associated with a fall in pulse rate from 72 to 68 beats a minute, but no significant change in the blood pressure.

The average standard error of the mean for the cardiac output of all subjects was \pm 6 per cent. The average maximum deviation from the mean was 10 per cent. In 10 subjects blood samples were obtained during the tail of the dilution curves for dye analysis. A mean value was used for each individual to convert area to litres per minute. The average cardiac output for the 10 subjects 


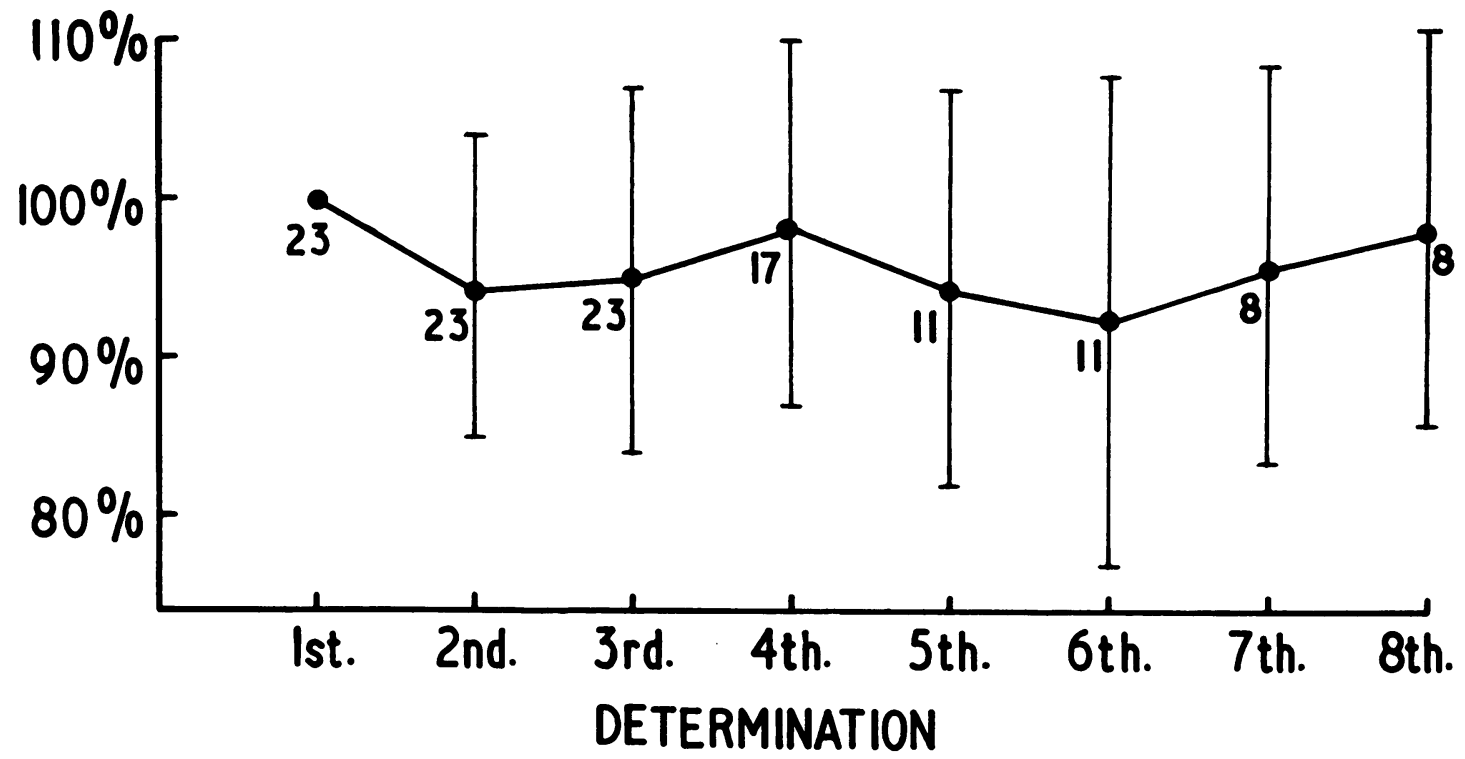

FIG. 2.-Per cent variation of the normal resting cardiac output at five minute intervals from all subjects. The vertical bars reflect the standard deviation and the figures represent the number of subjects included in each determination.

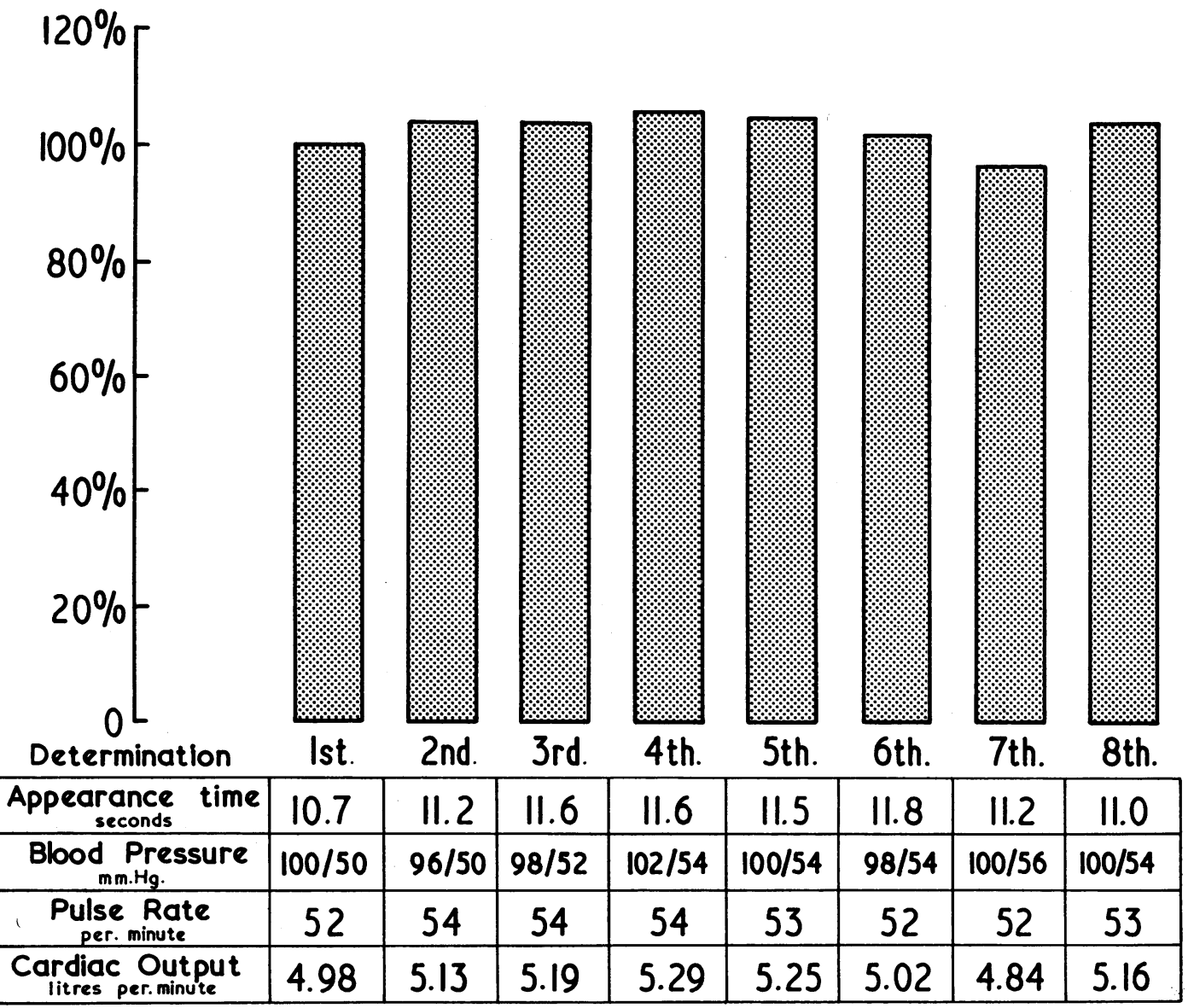

Fig. 3.-Fluctuations in the cardiac output in Subject No. 2, with dye appearance time, blood pressure, pulse rate and absolute cardiac output values given. 


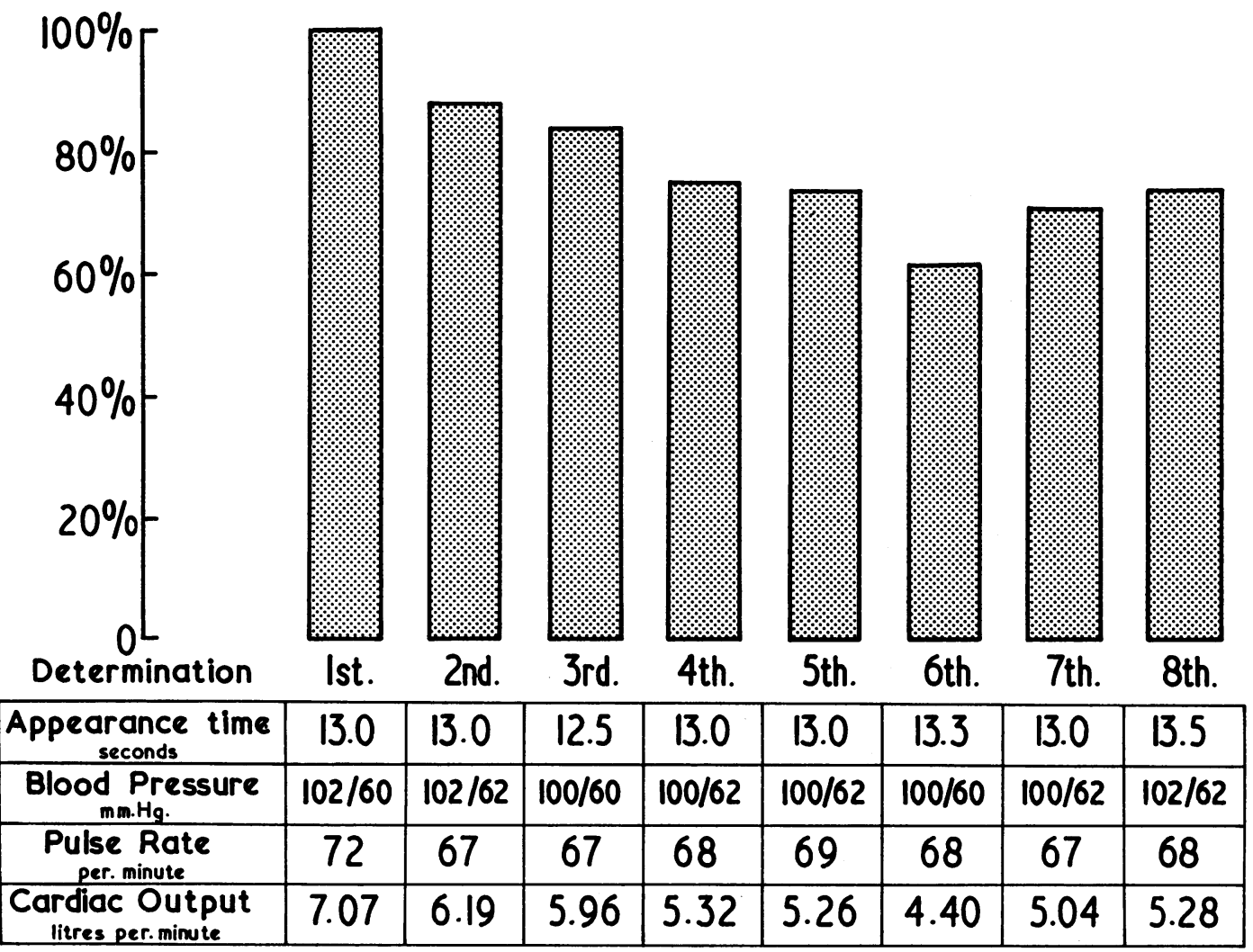

FIG. 4.-Fluctuations in the cardiac output in Subject No. 16, with dye appearance time, blood pressure, pulse rate and absolute cardiac output values given.

(72 dilution curves) was 5.74 litres per minute; the average cardiac index was 3.17 litres per minute per square metre body surface.

\section{Discussion}

Most of the previous studies to determine variations in the normal cardiac output have been made with two determinations, or occasionally with three (Cournand et al., 1945; Warren et al., 1945-6; Werko et al., 1949; Tanner, 1949; Chapman et al., 1950; Doyle et al., 1953; Gilmore et al., 1954). The direct Fick procedure involves cardiac catheterization, oxygen uptake measurements and arterial sampling, all having an effect on the basal state of the patient. Evans Blue dye causes tissue staining with repeated injections and other indicator dyes have undesirable side effects in adequate doses. The method described in this report was developed to avoid these complications and enable a detailed study of repeated cardiac outputs in subjects lying quietly at rest.

The results show that the cardiac output may vary as little as \pm 2 per cent in a resting individual over a 40 minute period. Only six subjects out of the 23 maintained a relatively stable output throughout the period of study, however; during the first few determinations two subjects showed a progressive increase in output and eleven subjects showed a progressive fall. The group average for the physicians showed no change on the second determination whereas the hospital patient group fell an average of 7 per cent on the second determination. This would suggest that there was an initially high cardiac output in these patients due to apprehension, and that they were not truly resting. The physicians were not as apt to feel frightened by the procedure. 
It is difficult to surmise how much of the change observed was due to the method and how much to real change in the cardiac output. If the first determination is excluded as being abnormally high due to excitement, the average error becomes less. Even so, it is probable that some of the subjects had not reached a basal state until the third or fourth determination, if ever. If the results of the last four determinations are analysed in the eight subjects who had eight determinations each, the standard error of the mean falls to \pm 3 per cent.

The areas of the dilution curves can be compared more accurately than the determined cardiac outputs because errors in the height of the tail of the dye curve are not included in the former. For example, a one $\mathrm{mm}$. error in measurement of the tail one $\mathrm{cm}$. high causes a 10 per cent error in calculated cardiac output. The likelihood of change in the baseline is minimal in the first 30 seconds, when the main dye curve is recorded, but shift may more easily occur before the three and five minute blood samples for dye analysis.

Peripheral venous injections have proved satisfactory in all cases where the arm was raised to speed drainage; slight variations in appearance time and downslope of the curves were not rejected as inaccuracies in the output, as shown by earlier circulation model studies (Hoffman and Shillingford, 1957). A total of approximately $200 \mathrm{mg}$. of Coomassie Blue dye has been used in each patient with no evidence of toxicity or skin discolouration.

The validity of the method depends on the reliability of the earpiece technique for estimating cardiac output (Lee, 1960). It requires that the earpiece response, and that of the recording apparatus, be linear during the build up of dye background in the blood. It necessitates the earpiece being maintained in exactly the same position throughout all measurements in order to record the optical density of a vascular bed of constant area. It assumes that the mean blood flow through the ear does not change during the recording.

The earpiece and recorder used in this laboratory have been found to give satisfactorily linear response to increasing concentrations of dye within the range required (Gabe and Shillingford, 1961). The earpiece position can be maintained by proper attachment to the pinna and by taping the cord to the forehead. Ear blood volume is likely to be constant if the cardiac output is constant and if the ear vessels are maintained in a constant environment, such as that produced by a dilatation from histamine cream and direct exposure to the warm lamp situated inside the earpiece. In situations of changing cardiac outputs it has been shown that earpiece and femoral arterial cuvette dye curves move proportionately in the same direction (Tuckman, Gabe and Shillingford, personal communication). The reproducibility of the results further emphasises that in the resting state a change in the vascularity of the ear plays only a small part, if any, in alterations of the cardiac output.

The main advantage of the method is its simplicity. It can be used at the patient's bedside and involves no more discomfort than a venipuncture. It can be repeated as often as is desirable. It has potential use in various therapeutic investigations and offers special promise in evaluating those conditions in which the cardiac output is unstable, such as acute myocardial infarction and the hypertensive states.

\section{SUMmaRY}

A simple method for serial estimation of the cardiac output has been described, using an earpiece cuvette and Coomassie Blue dye. In 23 normal resting subjects 115 dye dilution curves were made. The average standard error of the mean in all subjects was \pm 6 per cent, or if only the last four determinations for each individual are analysed to minimize actual changes in the cardiac output, \pm 3 per cent. The cardiac output of hospital patients fell an average of 7 per cent on the second determination and remained relatively stable thereafter. In 10 subjects absolute values were obtained with this method; the average cardiac output was 5.74 litres per minute and the average cardiac index was $3 \cdot 17 \pm 0 \cdot 22$ litres per minute per square metre body surface.

\section{REFERENCES}

Berseus, S. (1943). Acta med. Scandinav., supp. 146.

Chapman, C. B., Taylor, H. L., Borden, C., Ebert, R. V., and Keys, A. (1950). J. clin. Invest., $29,651$. 
Christiansen, J. C., Douglas, G., and Haldane, J. S. (1914). J. Physiol., 48, 244.

Cournand, A., Riley, R. L., Breed, E. S., Baldwin, E. de F., and Richards, D. W. Jr. (1945). J. clin. Invest., $24,106$.

Donald, K. W., Bishop, J. M., Cumming, G. and Wade, O. L. (1955). Clin. Sci., 14, 37.

Doyle, J. T., Wilson, J. S., Lepine, C., and Warren, J. V. (1953). J. lab. and clin. Med., $41,29$.

Gabe, I., and Shillingford, J. (1961). Brit. Heart J., 23, 271.

Gilmore, H. R., Hamilton, M., Kopelman, H., and Sommer, L. S. (1954). Brit. Heart J., 16, 310.

Goodyer, A. V., Chetrick, A., and Huvos, A. (1960). Yale J. Biol. Med., 32, 250.

Grollman, A. (1928). Am. J. Physiol., 86, 285.

Hamilton, W. F., Moore, J. W., Kinsman, J. M., and Spurling, R. L. (1932). Am. J. Physiol., $99,534$.

Hoffman, J. I. E., and Shillingford, J. P. (1957). Clin. Sci., 16, 1.

Krogh, A., and Lindhard, J. (1912). Skandinav. Arch. f. Physiol., 27, 100

Lee, G. de J. (1960). Clinical Disorders of the Pulmonary Circulation, 20, Churchill, London.

McMichael, J., and Sharpey-Shafer, E. P. (1944). Brit. Heart J., 6, 33.

Nylin, G. (1933). Acta med. Scandinav., suppl. 52.

Reeves, J. T., Grover, R. F., Filley, G. F., and Blount, S. G. Jr. (1961). J. applied Physiol., $16,276$.

Stead, E. A. Jr., Warren, J. V., Merrill, A. J., and Brannon, E. S. (1945). J. clin. Invest., $24,326$.

Stewart, G. N. (1921). Am. J. Physiol., 58, 20.

Tanner, J. M. (1949). J. clin. Invest., 28, 567.

Taylor, S. H., and Shillingford, J. P. (1959). Brit. Heart J., 21, 497.

Warren, J. V., Stead, E. A. Jr., and Brannon, E. S. (1945-6). Am. J. Physiol., 145, 458.

Werko, L. (1947). Acta med. Scandinav., suppl. 193.

-, Bereus, S., and Lagerlof, H. (1949). J. clin. Invest., 28, 516. 